\title{
Surface Studies of $\mathrm{UFe}_{3}$ and Evaluation \\ of its Catalytic Properties \\ With a $2 \mathrm{H}_{2}$ : $\mathrm{CO}$ Mixture
}

\section{d. Schultz \\ J. Naegele \\ J. Spiriet}

C. Colmenares

This paper was prepared for The 2nd Int' 1

Conference on the Basic a Applied Chemistry

of $f$-Transition (Lanthanide \& Actinide) arid

Related Elements, Lisbon, Portugal, 4/6-10/87

March 24, 1987

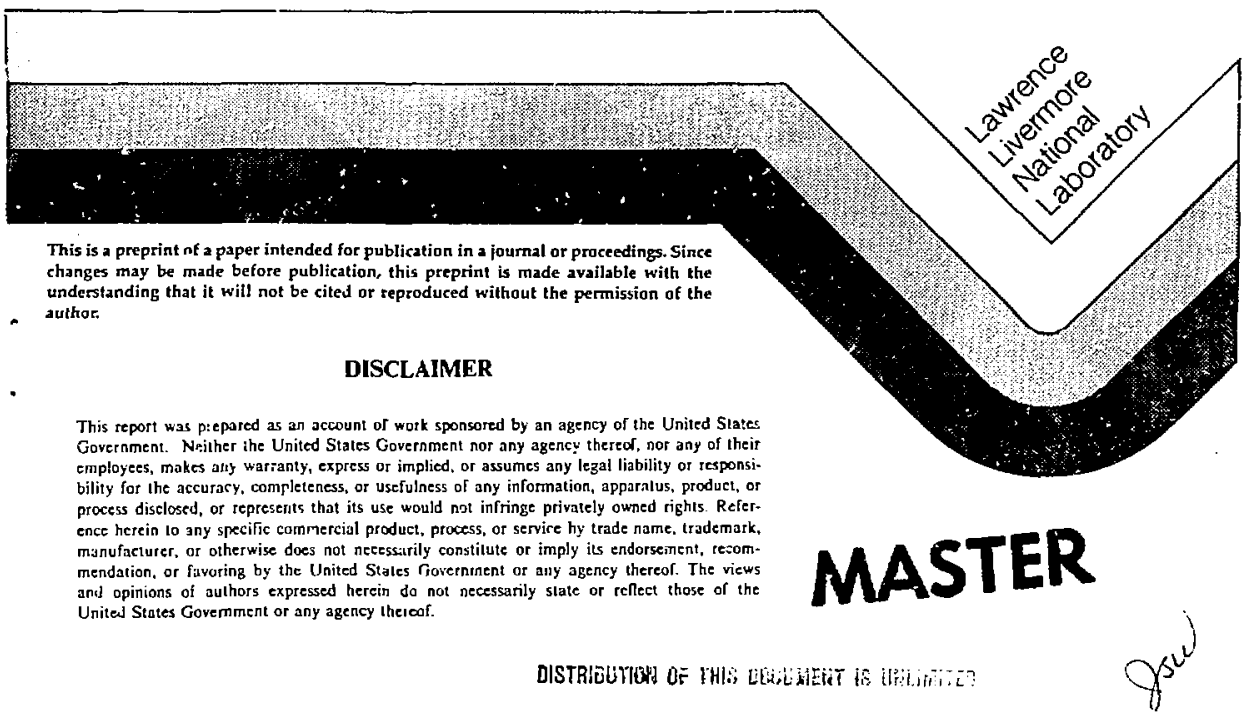


Surface Studies of UFe 2 and Evaluation of its Catalytic Properties with a $2 \mathrm{H}_{2}$ : $\mathrm{CO}$ Mixture $*$

J. Schultz, J. Naegele ${ }^{*}$, J. ¿. Spirlet ${ }^{\star}$ and C. Colmenarest

$$
\begin{gathered}
\text { University of California } \\
\text { Lawrence Livermore National Laboratory } \\
\text { P. 0. Box } 808 \\
\text { Livermore. CA } 94550 \text {, USA } \\
\text { *Commission of the European Communities } \\
\text { European Institute for Transuranium Elements } \\
\text { Postfach } 2340 \text {, D-755? } \\
\text { Karlsruhe, Federal Republic of Germany }
\end{gathered}
$$

\section{Abstract}

The reactivity of $\mathrm{UFe}_{2}$ with $\mathrm{U}_{2}, \mathrm{CO}$ and $\mathrm{CO}_{2}$ were studied using $\mathrm{x}$-ray photoelectron spectroscopy (XPS). Adsorption of $\mathrm{O}_{2}$ on clean UFe $\mathrm{U}_{2}$ surfaces $(\mathrm{Fe} / \mathrm{U}=2.0$ ), produced by argon-ion sputtering, leads to the formation of $\mathrm{UO}_{2}$ and depletion of Fe from the surface layer probed by XPS ( $\mathrm{Fe} / \mathrm{U}=0.8$ ). The oxidation state of $\mathrm{Fe}$ in this layer, as determined by XPS (Fe $2 \mathrm{p}_{3 / 2}=$ $7(0.4 \mathrm{eV})$, is between $\mathrm{Fe}^{+2}$ and $\mathrm{Fe}^{+3}$ of pure $\mathrm{Fe}$ oxides. Exposure of sputtered-clean $\mathrm{UFe}_{2}$ to $\mathrm{CO}$ and $\mathrm{CO}_{2}$ results in a slight broadening of the $\mathrm{U}$ $4 f$ peaks indicating $U$ oxidation, and some Fe depletion in the analyzed layer (Fe/Un 1.7 ). The 0 Is ( 530.2 and $530.4 \mathrm{eV}$ for $\mathrm{CO}$ and $\mathrm{CO}_{2}$, respectively) and $\mathrm{C}$ Is (282.7 and $282.6 \mathrm{eV}$ for $\mathrm{CO}$ and $\mathrm{CO}_{2}$, respectively) indicate that dissociative chemisorption to 0 and $\succsim$ atoms occu:s.

$\mathrm{UFe}_{2}$ ground into a fine powder was tested as a cat:'yst in a differential high-pressure flow reactor with a $2 \mathrm{H}_{2}$ : $\mathrm{CO}$ gas mixture. A significant amount of methanol and hydrocarbons are produced at 577K; while hydrccarbons are the main products (>99\%) at 739K. XPS analysis of the usad catalyst indicates that $U$ is present as $\mathrm{UO}_{2+\mathrm{x}}$ and $\mathrm{Fe}$ as $\mathrm{Fe}_{2} \mathrm{O}_{3}$.

Work performed under the auspices of the U. S. Department of Energy thy the Lawrence Livermore National Laboratory under contract number H-7405-ENG-48.

+Authar to whom correspondence should be addressed. 


\section{Introduction}

As part of a long term program to study the catalytic properties of actinides and their intermetallic compounds, we have investigated the highpressure reaction of $\mathrm{H}_{2}$ and $\mathrm{CO}$ to form hydrocarbons over crushed $\mathrm{UFe}_{2}$ and the ccmplimentary reacitions of $\mathrm{O}_{2}, \mathrm{CO}$ and $\mathrm{CO}_{2}$ with the surface of polycrystalline $\mathrm{UFe}_{2}$, studied under ultra-high vacuum conditions.

\section{Experimental}

The surface reactions were followed by $x$-ray photoelectron spectroscopy (XPS) using $A 1 \mathrm{~K} \alpha$ radiation and a double pass CMA (FWH Au 4f $7 / 2=2.0$ eV). Sample cleaning was performed by argon ion (2-3kV) bombardment, which is expected to result in a slight depletion of Fe from the surface.

The high-pressure reactions were carried out in a copper-lined, differential flow reactor and the products analyzed by gas chromatography. A $2 \mathrm{H}_{2}$ : $1 \mathrm{CO}$ mixture at 50 atmospheres was passed over $3 \mathrm{~s}_{5}$ of finely ground $\mathrm{UFe}_{2}$

\section{Results and Discussion}

The surface composition of an initially sputtered-clean surface of $\mathrm{UFe}_{2}$, as a function of $\mathrm{O}_{2}$ exposure, is shown in Figure 1 . Atomic concentrations are calculated using empirically derived sensitivity factors for the U $4 f$, Fe $2 p$ and 0 is core level peaks [ 1$]$, thus the resulting concentrations may only be accurate to $25 \%$ al though relative concentration changes are much more reliable. For a sputtered-clean $\mathrm{UFe}_{2}$ surface the binding energies of the U $4 f_{7 / 2}$ and $\mathrm{Fe} 2 p_{3 / 2}$ core levels are 377.8 and $707.1 \mathrm{eV}$, respectively, 
and the Fe/U ratio is $=2.0$. Progressively more of the uranium is oxidized to $\mathrm{UO}_{2}$ for exposures from 5 to $80 \mathrm{~L} \mathrm{O}_{2}$. This assignment is made on the basis of new $U$ $4 f$ peaks which contain an increasingly larger fraction of the total $U 4 f$ intensity as a function of exposure. The $U 4 f_{7 / 2}$ peak for $\mathrm{UO}_{2}$ appears at $380.2 \mathrm{eV}$ and its distinctive shakeup satellite is $6.7 \mathrm{eV}$ from the U $4 f_{5 / 2}$ peak [2]. After a $80 \mathrm{~L} \mathrm{O}_{2}$ exposure, the uranium in the surface region analyzed ( $\approx 50 A)$ is completely oxidized. The Fe $2 p$ spectrum shows no significant change up to this level of oxygen exposure indicating that the iron remains metallic. The Fe/U ratio decreases dramatically with exposures from 5 to $80 \mathrm{~L} \mathrm{O}_{2}$ (Fig. I) suggesting that uranium is segregating to the surface, driven by $\mathrm{UO}_{2}$ formation.

Iron oxidation occurs with oxygen exposure from $160 \mathrm{~L}$ to $1280 \mathrm{~L} \mathrm{O}_{2}$ as indicated by an increasing fraction of the $\mathrm{Fe} 2 p_{3 / 2}$ and $2 p_{1 / 2}$ peak intensities appearing $=3 \mathrm{eV}$ higher than their metallic positions. There is a slight increase in the Fe/U ratio accompanying the iron oxidation (Fig. I), suggesting a partial reversal of the segregation of uranium to the surface observed at lower oxygen exposures. From $1280 \mathrm{~L}$ to $5120 \mathrm{~L} \mathrm{O}_{2}$, the binding energy of the Fe $2 p_{3 / 2}$ peak is $310.4 \mathrm{eV}$. which falls between the values determined for $\mathrm{Fe}^{+2}$ and $\mathrm{Fe}^{+3}$ species in pure iron oxides, 709.7 and 711.2 eV [3], respectively. However, the Fe $2 p_{3 / 2}$ peak shape does not appear to indicate the presence of both species. The poor match of our results with the binding energies observed for pure iron oxides may reflect the formation of a $U_{x} \mathrm{Fe}_{y} \mathrm{O}_{z}$ mixed oxide.

Annealing this highly oxidized sample up to $673 \mathrm{~K}$, followed by cooling to $\approx 323 K$ to take photoelectron spectra, reduces the iron to its metallic state 
and produces a dranatic decrease in the Fe/U ratio (Fig. 1), resulting from additional $\mathrm{UO}_{2}$ segregation to the surface. Also, the $U 4 \mathrm{i}, U \mathrm{Ud}, 0$ Is and $U$ $5 f$ peaks shift to higher binding energies by $0.7 \mathrm{eV}$. An explanation for this observation is thät annealing causes an upward shift of the Fermi level within the band gap of uranium oxide.

The reactions of $\mathrm{CO}$ and $\mathrm{CO}_{2}$ with the sputtered-clean $\mathrm{UFe}_{2}$ surface are very similar to each other and distinctly different from that of $\mathrm{O}_{2}$ in that they saturate at about $20 \mathrm{~L}$ gas exposure. These reactions cause some segregation of uranium to the surface (Fe/U $=1.7$ ). $20 \mathrm{~L}$ of either $\mathrm{CO}$ or $\mathrm{CO}_{2}$ results in an 0 is peak at 530.4 or $530.2 \mathrm{eV}$, respectively, very close to the 0 Is peak at $530.4 \mathrm{eV}$ after $20 \mathrm{~L} \mathrm{O}_{2}$. Binding energies of 282.7 or $282.6 \mathrm{eV}$ for the $\mathrm{C}$ Is core level after $\mathrm{CO}$ or $\mathrm{CO}_{2}$ exposure, respectively, are very close to values observed for atomic $\mathrm{C}$ on other metals [4]. A broadening of the $U 4 f$ peaks, but no change in the Fe $2 p$ spectrum, is observed compared to the spectrum of the clean surface. Thus the spectra indicate that $\mathrm{CO}$ and $\mathrm{CO}_{2}$ dissociate on the sputtered-clean surface of UFe ${ }_{2}$ and that the oxygen reacts with uranium to form uranium oxide. Using empirically derived sensitivity factors [I], the $0 / C$ ratios calculated after saturation $w i$ th $C O$ and $\mathrm{CO}_{2}$ are 2.0 and 3.6 , respectively. These are larger than the stoichiometry of the reacting gases. Also, the $0 / C$ ratio is about two times larger in spectra taken from a grazing angle $\left(\approx 10^{\circ}\right)$, where the surface sensitivity of the technique is further enhanced, than in spectra taken from a normal angle of incidence. These observations are consistent with the oxygen atoms being on the surface of the solid and the carbon atoms being deeper into the analyzed layer. 
$\mathrm{UFe}_{2}$ was tested as a catalyst with a $2 \mathrm{H}_{2}: 1 \mathrm{CO}$ mixture under the same conditions used to produce methanol over $\mathrm{ThO}_{2}$ [5]. Preliminary results show that $\mathrm{UFe}_{2}$ produces a significant anount of methanol (6I.8 weight $\%$ of the products) at $577 \mathrm{~K}$, but that hydrocarbons are the main products at $739 \mathrm{~K}$. The product distribution in $w$ t $\%$ is: 25.4 methane, 4.2 ethylere, 6.4 ethane, 23.6 propane, 21.8 i-butane, 4.0 n-butane, 5.4 i-pentane, 3.8 n-pentane, 5.4 n-heptane, and $<0.2$ methanol. The 25.4 wt $\%$ methane of the products represents 0.14 wt $\%$ in the effluent gas. Four unidentified products with more than eight carbons are also detected. The hydrocarbon products at both temperatures follow the product distribution predicted by the Schulz-Flory polymerization model. Raising the reactor to $783 \mathrm{~K}$ after 108 hours at $577 \mathrm{~K}$ causes severe coking of the catalyst. XPS analysis of the used catalyst indicates that uranium is piesent as $\mathrm{WO}_{2+x}$ and iron as $\mathrm{Fe}_{2} \mathrm{C}_{3}$, with a $\mathrm{Fe} / \mathrm{U}$ ratio of 1.2 .

\section{References}

I. C. D. Wagner, L. E. Davis, M. V. Zeller, J. A. Taylor, R. H. Raymond and L. H. Gale, Eurf. Interface Anal., 3, 21/(!981).

2. G. C. Allen, P. M. Tucker and J. W. Tyler, J. Phys. Chen., 86, 224(1982).

3. C. R. Brundle, T. J. Chuang and K. Wandelt, Surf. Sci., 68, 459(1S77).

4. C. R. Brundle, IBM J. Res- Develop., 22, 235(1978).

5. J. Maj, C. A. Colmenares and G. A. Somor jaí, ‥ Catal., 95, 385(1985). 


\section{Figure 1}

Atomic percent obtained from XPS of initially sputtered-clean UFe 2 surface after exposure to $\mathrm{O}_{2}$ and then annealing. Oxidation states of $U$ and $\mathrm{Fe}$ are indicated. 


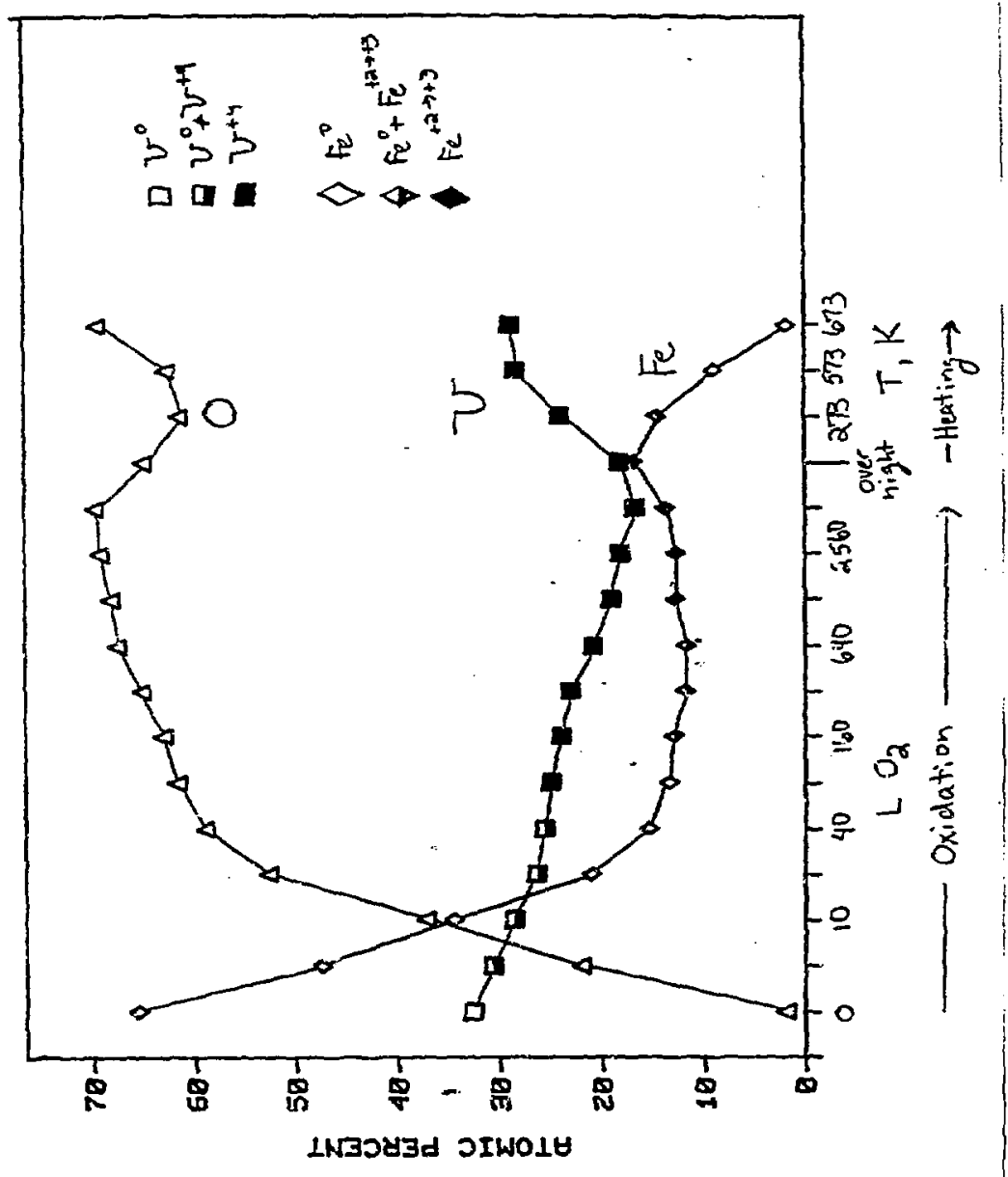




\section{DISCLAMER}

This document wis prepered as an account of work sponsored by an agency of the United States Government. Neither the United Stales Govemnent nar the University of Californiz nor any of their employees, makes any warranty, express or implied, or assumes any legal liability or responsibility for the accurscy, campleteness, or useluliness of any information, apparetes, product, or process disclosed, or represenls that its use wruld not infringe privatety owned rights, Refercnce berein to any specific conmezcial produrts, process, or service by truds nams, tradema-k, manufjecturer, of otherwise, does not necessatily constitute or imply its cadorsement, resammendation, or favoring by the United States Government or the University of California. The vicus and opinions of authors expressed herein do not necessariiy state ar reflect thase of the United Stales Governmest thareof, and shall not te uscd for advertisiog or product endorsement purposes. 